\title{
AKTIVITAS LOMPAT TINGGI
}

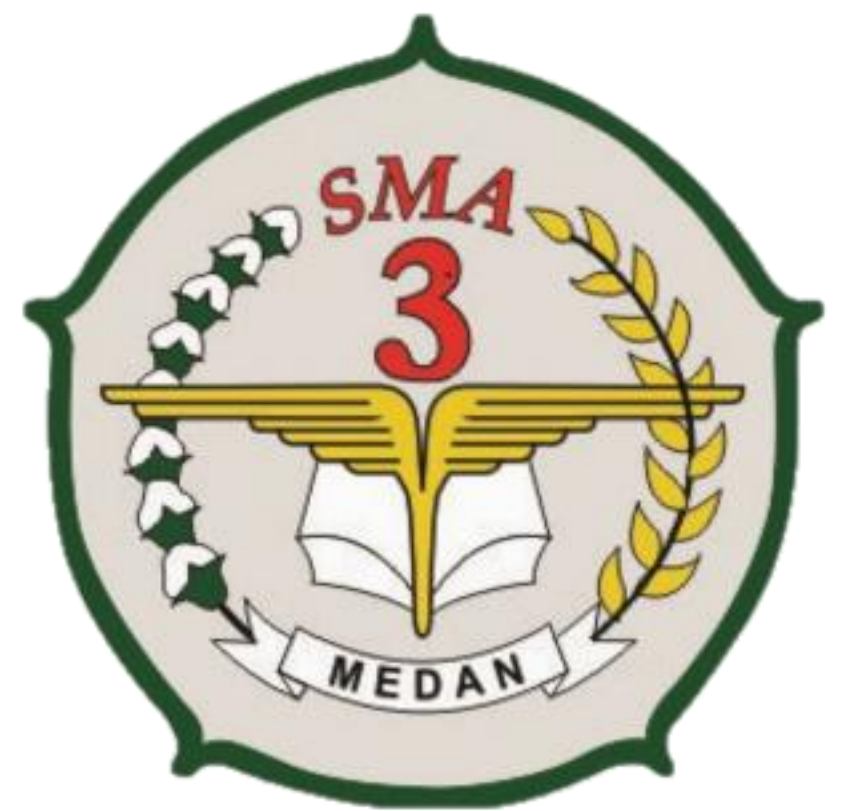

OLEH:

NAZWA DWI ARCHIKA

X MIA-I

PENDIDIKAN JASMANI DAN KEBUGARAN

SMA NEGERI 3 MEDAN

TAHUN AJARAN 2019/2020 


\section{KATA PENGANTAR}

Segala puji bagi allah swt atas segala rahmat yang telah di berikan kepada saya sehingga saya bisa menyusun makalah ini tentang Lompat tinggi.

Makalah ini saya buat saya usahakan dapat di mengerti saya sendiri dan orang lain, bila ada kesalahan mohon kritik dan saran yang bersifat membangun, agar bisa perbaikan pembuatan makalah untuk selanjutnya.

Akhir kata, mudah-mudahan makalah ini memberi manfaat dalam kegiatan belajar mengajar, khususnya dalam perkuliahan sehingga dapat mempermudah dalam proses pembelajaran.

Medan, April 2020 


\section{BAB I}

\section{PENDAHULUAN}

\section{A. Latar Belakang Masalah}

Masyarakat Indonesia, dalam era globalisasi ini tidak dapat menghindar dari arus derasnya kompleksitas perubahan (Inovasi) sebagai akibat canggihnya teknologi informasi, telekomunikasi, tatanan ekonomi dunia yang mengarah pada pasar bebas,serta tingkat efisiensi dan kompetitif yang tinggi di berbagai bidang kehidupan. Suka/ tidak suka, mau/tidak bangsa Indonesia harus mengikutinya jika tidak akan ketinggalan dan mungkin disebut Negara "primitif"

Globalisasi adalah suatu proses tatanan sosial yang mendunia dan tidak berbatas atau tak mengenal batas wilayah. Globalisasi adalah suatu proses dari gagasan yang sengaja dicari dan dimunculkan, kemudian ditawarkan untuk diikuti oleh bangsa lain yang akhirnya sampai pada suatu titik kesepakatan bersama dan menjadi pedoman bersama bagi bangsa- bangsa di seluruh dunia. (Menurut Edison A. Jamli dkk.Kewarganegaraan.2005)

Menurut pendapat Krsna (Pengaruh Globalisasi Terhadap Pluralisme Kebudayaan Manusia di Negara Berkembang.internet.public jurnal.september 2005). Sebagai proses, globalisasi berlangsung melalui dua dimensi dalam interaksi antar bangsa, yaitu dimensi ruang dan waktu. Ruang makin dipersempit dan waktu makin dipersingkat dalam interaksi dan komunikasi pada skala dunia. Globalisasi berlangsung di semua bidang kehidupan seperti bidang ideologi, politik, ekonomi, sosial budaya, pertahanan keamanan dan lain- lain. Oleh karena itu globalisasi tidak dapat kita hindari kehadirannya.Kehadiran globalisasi tentunya membawa pengaruh bagi kehidupan suatu negara termasuk Indonesia.Pengaruh tersebut meliputi dua sisi yaitu pengaruh positif dan pengaruh negatif.

Dalam kehidupan modern, manusia tidak dapat dipisahkan dari olahraga, baik sebagai media adu prestasi maupun sebagai kebutuhan untuk menjaga kondisi tubuh agar tetap sehat. Olahraga mempunyai peranan penting dalam kehidupan manusia. Melalui olahragalah manusia dapat dibentuk menjadi sehat jasmani dan rohani, serta mempunyai kepribadian, disiplin, dan sportivitas yang tinggi sehingga pada akhirnya akan terbentuk manusia yang berkualitas. Lompat tinggi merupakan salah satu bagian dari cabang olahraga atletik. Lompat tinggi adalah salah satu keterampilan untuk melewati mistar yang dipasang di kedua tiang. Tujuan dari lompat tinggi adalah mendapatkan lompatan yang setinggi mungkin. Ketinggian lompatan yang dicapai 
oleh pelompat ditentukan oleh kemampuan dan persiapan bertanding dari masing-masing pelompat. Hingga saat ini, ada empat gaya yang dikenal dalam lompat tinggi, diantaranya adalah gaya guling (Straddle) yang merupakan gaya dimana ketika badan melewati mistar dengan cepat diputar dan dibalikkan, sehingga sikap badan di atas mistar telungkup.

\section{RUMUSAN MASALAH}

Adapun beberapa permasalahan berdasarkan latar belakang di atas yang akan dibahas adalah sebagai berikut :

1. Sejarah lompat tinggi

2. Pengertian lompat tinggi

3. Peraturan dalam permainan lompat tinggi

4. Teknik-teknik dalam permainan lompat tinggi

5. Media dalam permainan lompat tinggi

6. Informasi lain seputar lompat tinggi

\section{TUJUAN \& MAKSUD}

Adapun beberapa tujuan berdasarkan rumusan masalah di atas yang hendak dicapai adalah sebagai berikut :

1. Mengetahui sejarah lompat tinggi

2. Mengetahui pengertian lompat tinggi

3. Mengetahui peraturan dalam permainan lompat tinggi

4. Mengetahui teknik-teknik yang digunakan dalam permainan lompat tinggi

5. Mengetahui sarana dan prasarana yang digunakan dalam permainan lompat tinggi

6. Mengetahui informasi lain seputar lompat tinggi 
BAB II

PEMBAHASAN

\section{A. Sejarah Lompat Tinggi}

Lompat tinggi bermula dari olimpiade pada abad ke-19 di Skotlandia. Pada kala itu, para peserta lompat tinggi menggunakan gaya gunting dan tercatat lompatan tertinggi yang dilakukan oleh peserta adalah 1,68 meter. Pada saat itu juga, lompat tinggi tidak dilakukan secara sembarangan. Ada gaya-gaya tertentu yang harus dikuasai agar peserta terhindar dari kecelakaan. Pada abad ke-19, peserta lompat tinggi mendarat dan jatuh di atas tanah yang berumput dengan gaya gunting (dengan cara membelakangi) yang ternyata banyak meng-akibatkan cedera bagi para peserta.

Kemudian pada sekitar abad ke 20, gaya lompat tinggi telah dimodernisasi oleh seorang warga Irlandia-Amerika bernama Michael Sweeney. Pada tahun 1895, Michael Sweeney berhasil melakukan lompatan setinggi 1,97 meter gaya eastern cut-off, dimana mengambil off seperti gunting, tapi memperpanjang punggungnya dan mendatar di atas bar.

Warga Amerika lainnya bernama George Horine mengembangkan teknik lompat yang lebih efisien bernama Western Roll. Melalui teknik ini, Horine bisa mencapai lompatan setinggi 2,01 meter pada tahun 1912. Kemudian pada Olimpiade Berlin tahun 1936, teknik lompatan ini menjadi dominan dilakukan sehingga Cornelius Johnson berhasil menang dengan mencapai ketinggian $2.03 \mathrm{~m}$.

Kemudian pada empat dekade berikutnya, pelompat Amerika dan Soviet telah merintis evolusi teknik straddle. Charles Dumas adalah orang pertama yang menggunakan teknik ini mencapai ketinggian 2,13 m pada tahun 1956. Kemudian warga Amerika, John Thomas meningkatkan rekor dunia dengan ketinggian lompatan 2.23 m pada tahun 1960. Dan akhirnya Valeriy Brumel mengambil alih pencapaian dalam empat tahun ke depan. Pelompat Soviet ini mencatat ketinggian lompatan hingga 2,28 $\mathrm{m}$ dan berhasil memenangkan medali emas pada olimpiade tahun 1964, sebelum kecelakaan sepeda motor mengakhiri karirnya.

Dari Brumel inilah para atlet lompat tinggi mencoba belajar dan mengembangkan olahraga lompat tinggi hingga saat ini terdapat berbagai gaya dalam olahraga lompat tinggi di dunia, antara lain gaya gunting (Scissors), gaya guling sisi (Western Roll), gaya guling (Straddle) dan gaya fosbury flop. Sementara kini, lompat tinggi dilakukan dengan mendarat di atas matras sehingga kecelakaan dapat diminimalisir. Atlet lompat tinggi sekarang banyak menggunakan gaya fosbury flop.

\section{B. Pengertian Lompat Tinggi}

Lompat tinggi merupakan salah satu cabang olahraga yang melakukan gerakan lompatan untuk mencapai lompatan yang setinggi-tingginya. Ukuran lapangan sama dengan lompat jauh,

Tinggi tiang mistar min 2.5 meter, Panjang mistar $3.15 \mathrm{~m}$. 


\section{Tahapan pada lompat tinggi}

Semua gaya lompatan dapat dibedakan menjadi 4 tahap, yaitu :

a) Awalan, gerakan berlari menuju mistar

b) Tolakan, gerakan kaki menumpu pada lantai untuk menaikkan badan

c) Melayang, gaya dan kedudukan badan ketika berada di udara dan di atas mistar.

d) Mendarat, jatuhnya badan diatas matras.

\section{Peraturan Lompat Tinggi}

Sebelum perlombaan dimulai, ketua juri harus mengumumkan kepada segenap peserta lomba mengenai tinggi mistar permulaan dan tinggi berikutnya. Mistar lompat akan dinaikkan pada akhir tiap babak/ronde sampai hanya tersisa satu orang peserta lompat tinggi yang memenangkan perlombaan, atau terjadi hasil sama untuk kedudukan pertama. Apabila terjadi hasil sama, pemenang dilihat dari kegagalan terkecil selama perlombaan dan ketinggian yang terakhir yang dilewatinya.

Dalam pertandingan, mistar akan dinaikkan setelah pelompat berhasil melewati ketinggian mistar. Pelompat boleh mulai melompat pada ketinggian permulaan yang disukainya dengan ketinggian minimal $2,5 \mathrm{~m}$. Lompatan dianggap batal apabila pelompat menyentuh palang atau tidak melompat. Pelompat yang menjatuhkan palang atau menyentuh tanah termasuk daerah pendaratan di balik bidang tegak dari sisi dengan lebih dekat tiang lompat, baik itu diantara atau di luar tiang lompat dengan salah satu bagian dari tubuhnya, tanpa pertama kali melewati mistar lompat dianggap gagal. Setiap pelompat akan diberi peluang sebanyak tiga kali untuk melakukan lompatan. Jika pelompat tidak berhasil melewati mistar sebanyak tiga kali berturut-turut, dia dinyatakan gagal. Untuk menentukan kemenangan, para pelompat harus berusaha melompat setinggi mungkin yang dapat ia lakukan. Pemenang ditentukan dengan lompatan tertinggi yang dilewati. Peserta mestilah melonjak dengan sebelah kaki.Peserta boleh mula melompat di mana-mana ketinggian permulaan yang disukainya Sesuatu lompatan akan dikira batal jika peserta menyentuh palang dan tidak melompat. Menjatuhkan palang semasa membuat lompatan atau menyentuh kawasan mendarat apabila tidak berjaya melompat. Peserta yang gagal melompat melintasi palang sebanyak tiga kali bertutrut-turut (tanpa di ambil kira di aras mana kegagalan itu berlaku) akan terkeluar daripada pertandingan. Seseorang peserta berhak meneruskan lompatan (walaupun semua peserta lain gagal) sehingga dia tidak dapat menuruskannya lagi mengikut peraturan Ketinggian lompatan di ukur secara menegak dari aras tanah hingga bahagian tengah disebelah atas padang. 
E. Ada empat jenis gaya lompat tinggi yang umumnya digunakan oleh peserta lompat tinggi, antara lain sebagai berikut.

1. Teknik Gaya Guling (Straddle)

Gaya guling (Straddle) merupakan gaya dimana badan kita melewati tiang dengan cara diputar dan dibalikkan lagi sehingga sikap badan kita saat di atas mistar tertelungkup. Cara untuk melakukan gaya guling adalah pelompat harus mengambil awalan terlebih dahulu dari samping antara 3, 5, 7, atau 9 langkah. Tumpuan terletak pada kaki yang paling kuat, kemudian ayunkan ke depan. Setelah kaki diayunkan, dengan cepat badan kita balikkan untuk bisa melewati mistar sehingga sikap badan kita di atas mistar telungkup. Pantat kita usahakan lebih tinggi dari kepala kita, jadi kepala agak menunduk. Pada waktu mendarat gunakan kaki kanan dan tangan kanan jika tumpuan menggunakan kaki kiri, begitu pula sebaliknya.

Cara lainnya adalah dengan mengambil jarak awalan dari samping antara 4, 6, 8, atau 10 langkah tergantung pada ketinggian target yang ingin dilewati. Jika meng-gunakan kaki kiri sebagai tumpuan, ayunkan kaki kanan ke belakang menuju depan. Setelah kaki ayunan melewati mistar, kemudian posisi badan saat di udara atau di atas mistar dalam keadaan tengkurap. Posisi pinggang usahakan lebih tinggi dibandingkan dengan posisi kepala. Ketika posisi terjatuh, tumpuan berada di kedua tangan dan kaki ayunan yang pertama mendarat, lalu dilanjutkan dengan meng-gulingkan badan yang pertama (bagian punggung tangan) dan berakhir pada bahu.

Teknik awalan yang digunakan untuk teknik Straddle adalah mengambil posisi ancang-ancang yang tidak terlalu jauh, berlari dengan kecepatan sedang, posisi awalan dari samping sekitar $30^{\circ}$ atau $40^{\circ}$ dengan posisi tiang lompatan, dan berlari agak serong dari mistar; sedangkan teknik tolakan Straddle adalah menggunakan tumpuan kaki yang tersekat dengan mistar, posisi badan agak merebah atau sedikit condong ke belakang ketika akan melakukan tolakan, posisi kaki tumpuan menolak ke atas hingga kedua lutut kaki lurus dan kedua tangan dan kaki diayunkan dengan tenaga penuh ke depan. Teknik Straddle saat di atas mistar adalah posisi badan tengkurap dan posisi kaki harus segera diluruskan ke belakang ketika badan sudah mulai turun; sedangkan teknik mendarat Straddle adalah jika menggunakan tumpuan kaki yang kiri, maka posisi pendaratan memakai kaki kanan terlebih dahulu yang kemudian dilanjutkan dengan gerakan posisi berguling.

\section{Gaya Fosbury Flop}

Gaya ini diciptakan oleh Dick Ricarod Fosbury yang merupakan seorang pelompat tinggi dari Amerika Serikat. Keunikan dari gerakan Fosbury adalah tubuh berada di atas mistar dengan posisi terlentang dan jatuh menggunakan punggung yang masih dalam kondisi terlentang. Teknik ini merupakan kebalikan dari teknik Straddle, yakni punggung yang menghadap ke bagian bawah arah agak serong ke kiri, tidak lagi tegak lurus pada mistar.

Teknik awalan untuk gaya Flop adalah arahan dari depan, tegak lurus menghadap mistar. Jika menggunakan kaki kiri sebagai tumpuan, dari depan menuju tiang sandaran mistar sebelah kanan. Teknik tolakan untuk gaya Flop adalah menggunakan kaki terkuat pada tumpuan. Bila menggunakan kaki kiri, diangkat dengan lutut kaki ditekuk bersamaan dengan memutar badan ke arah awalan. Badan harus 
membelakangi mistar dan punggung berada di bagian bawah yang dekat dengan mistar dengan posisi punggung melengkung saat melewati mistar.

Teknik Flop saat di atas mistar adalah bagian kepala harus lebih dahulu melewati mistar dengan posisi badan yang terlentang dan punggung menghadap ke bawah arah mistar. Saat mencapai ketinggian yang maksimal dan pinggang melewati mistar, posisi kedua kaki digerakan atau diayun ke atas agar bisa melewati mistar dengan sempurna. Untuk pendaratan, bagian tubuh yang mendarat terlebih dahulu adalah punggung karena sikap tubuh yang terlentang saat melakukan pendaratan dan hanya boleh dilakukan dengan pendaratan pada bahan berbahan busa.

\section{Gaya Gunting (Scissors)}

Gaya ini ditemukan oleh Sweney, oleh karena itu juga sering disebut dengan Gaya Sweney. Sebelumnya di tahun 1880, Sweney menggunakan gaya jongkok, namun ia merasa gaya tersebut kurang tepat hingga akhirnya beliau mengubah gaya tersebut menjadi gaya gunting pada tahun 1896. Cara melakukan gaya gunting adalah mula-mula pelompat mengambil awalan dari tengah. Bila pelompat pada saat akan melompat menggunakan kaki kiri sebagai tumpuan lalu memakai kaki kanan sebagai ayunan, maka ia mendarat (jatuh) dengan kaki kanan juga.

\section{Gaya Guling Sisi (Western Roll)}

Gaya ini diciptakan oleh G. Horin yang berasal dari Amerika pada tahun 1912, namun gaya ini tidak dapat berkembang karena ada benturan dengan peraturan yang berlaku, dimana lompat tinggi menggunakan gaya guling sisi membuat posisi kepala cenderung lebih rendah dari pinggul kita saat kita melewati mistar, sehingga hal ini tidak sah. Oleh karena itu, gaya ini tidak pernah digunakan dalam lompat tinggi.

Ada beberapa hal yang patut diperhatikan oleh pelompat guna mencapai hasil yang maksimal (lompatan tertinggi). Beberapa hal yang perlu dihindari antara lain sebagai berikut.

1. Lari awalan yang terlalu cepat

2. Meluruskan kaki penolak terlalu jauh kedepan.

3. Gerak kombinasi kaki yang tidak sempurna.

4. Badan condong mendekati mistar.

5. Posisi tangan pada mistar terlalu tinggi.

6. Melewati mistar dalam posisi duduk.

7. Membuat lengkung badan terlalu awal.

8. Gerak terlambat dari gaerk angkat kaki akhir. 
Sedangkan berapa hal yang perlu diutamakan oleh pelompat adalah sebagai berikut.

1. Lari awalan dengan kecepatan yang terkontrol.

2. Menghindari kecondongan tubuh ke belakang terlalu banyak.

3. Mencapai gerakan yang cepat pada saat bertolak dan mendekati mistar.

4. Mengusahakan angkat vertikal pada saat take off atau pada saat kaki bertolak meninggalkan tanah.

5. Mendorong bahu dan lengan ke atas pada saat take off.

6. Melengkungkan punggung di atas mistar.

7. Mengusahakan mengangkat sempurna dengan putaran ke dalam dari ayunan lutut.

8. Mengangkat kemudian meluruskan kaki segera sesudah membuat lengkungan.

\section{BAB III}

PENUTUP

\section{A. KESIMPULAN}

Lompat tinggi merupakan olahraga yang menguji ketrampilan meompat dengan melewat tiang mistar.Lompat tinggi adalah salah satu cabang dari atletik. Tujuan olahraga ini untuk memperoleh lompatan setinggi-tingginya saat melewati mistar tersebut dengan ketinggian tertentu.Tinggi tiang mistar yang harus dilewati atlet minimal 2,5 meter, sedangkan panjang mistar minimal 3,15 meter. Lompat tinggi dilakukan di arena lapangan atletik.Lompat tinggi dilakukan tanpa bantun alat.

Dalam pertandingan, mistar akan dinaikkan setelah peserta berhasil melewati ketinggian mistar. Peserta mestilah melonjak dengan sebelah kaki Peserta boleh mulai melompat di mana-mana ketinggian permulaan yang disukainya Sesuatu lompatan akan dikira batal jika peserta menyentuh palang dan tidak melompat. Menjatuhkan palang semasa membuat lompatan atau menyentuh kawasan mendarat apabila tidak berjaya melompat Peserta yang gagal melompat melintasi palang sebanyak tiga kali bertutrut-turut (tanpa di ambil kira di aras mana kegagalan itu berlaku) akan terkeluar daripada pertandinga Seseorang peserta berhak meneruskan lompatan (walaupun semua peserta lain gagal) sehingga dia tidak dapat menuruskannya lagi mengikut peraturan Ketinggian lompatan di ukur secara menegak dari aras tanah hingga bahagian tengah disebelah atas padang.Setiap peserta akan diberi peluang sebanyak 
tiga kali untuk melakukan lompatan. Jika peserta tidak berhasil melewati mistar sebanyak tiga kali berturut-turut, dia dinyatakan gagal. Untuk menentukan kemenangan, para peserta harus berusaha melompat setinggi mungkin yang dapat dilakukan.Pemenang ditentukan dengan lompatan tertinggi yang dilewati Permainan lompat tinggi membutuhkan tempat yang tidak terlalu luas untuk memainkannya dan dapat dilakukan oleh pria maupun wanita. Dalam permainan lompat tinggi, diperlukan penguasaan berbagai teknik/gaya melompat guna tercapainya hasil yang maksimal dan sesuai harapan, yakni meraih lompatan tertinggi. Selain itu, juga terdapat beberapa ketentuan yang harus dipatuhi dan hal-hal yang perlu diperhatikan agar tidak terdiskualifikasi atau kalah. Olahraga lompat tinggi harus mulai diperkenalkan pada anak didik untuk menghasilkan bibit atlet yang berpotensi. Saat ini, pengenalan akan olahraga lompat tinggi kepada peserta didik di sekolah masih minim dikarenakan fasilitas yang kurang memadai. Oleh karena itu, pemerintah dan pihak sekolah perlu menambah fasilitas perolahragaan agar peserta didik dapat mengenal sekaligus berlatih olahraga lompat tinggi. Diharapkan akan muncul kader-kader baru dalam olahraga lompat tinggi yang dapat menorehkan hasil yang bagus di dunia olahraga dan membuat olahraga lompat tinggi terus berkembang. 


\section{DAFTAR PUSTAKA}

http://kumpulan-artikel-makalah.blogspot.com/2013/02/makalah-lompat-tinggi.html http://www.scribd.com/doc/142017172/LOMPAT-TINGGI

Diakses : Darussalam, tanggal 31 Mei 2010.

http://dianherlinawati.com/2010/04/04/kebugaran-jasmani/

Diakses : Darussalam, tanggal 31 Mei 2010.

http://onopirododo.wordpress.com/2010/01/27/makna-kesehatan-dan-kebugar an-jasmani/

Anonim (2015). Makalah Penjas : Olahraga Lompat Jauh.

Dari http://sepengatahuanku.blogspot.co.id/2015/01/makalah-penjas-olahraga-lom pat-jauh.html,

30 Juli 2017

Anonim (2017). Lompat Tinggi, Sejarah dan Gaya Teknik Lompat Tinggi, History of High Jump.

Dari http://www.berbagaireviews.com/2017/04/lompat-tinggi-sejarah-dan-gaya-te knik.html, 30

Juli 2017

Anonim (2015). Perbedaan Lompat Jauh dan Lompat Tinggi.

Dari http://areaperbedaan.blogspot.co.id/2015/09/perbedaan-lompat-jauh-dan-lom pat-tinggi.html,

30 Juli 2017

Ayu, Sarah (2014). Lompat Jauh dan Lompat Tinggi. Dari

http://tugas-anak-sekolah.blogspot.co.id

/2014/05/lompat-jauh-dan-lompat-tinggi.html, 30 Juli 2017

Jayus, Zuliaden (2014). Makalah Lompat Tinggi. Dari

http://zuliaden-jayus.blogspot.co.id/2014/08

/makalah-lompat-tinggi.html, 30 Juli 2017

Nur, Siti (2016). Teknik Lompat Tinggi Gaya Gunting (Scissors).

Dari https://aturanpermainan.blogspot.co.id/2016/04/teknik-lompat-tinggi-gaya-gu nting-

scissors.html, 30 Juli 2017

Yurissa, Putri Norma (2009). Peraturan Perlombaan Atletik Cabang Lompat Tinggi.

Dari https://lupiq.wordpress.com/2009/12/24/peraturan-perlombaan-atletik-caban g-lompat-

tinggi/, 30 Juli 2017 